\title{
Role of Sleep Disturbance in the Trajectory of Alzheimer's Disease
}

\author{
Dong Woo Kang ${ }^{1}$, Chang Uk Lee ${ }^{1}$, Hyun Kook Lim² \\ ${ }^{1}$ Department of Psychiatry, Seoul Saint Mary's Hospital, College of Medicine, Catholic University of Korea, Seoul, ${ }^{2}$ Department of Psychiatry, \\ Saint Vincent's Hospital, College of Medicine, Catholic University of Korea, Suwon, Korea
}

\begin{abstract}
Sleep disturbances such as insomnia, hypersomnia, and circadian rhythm disturbance are common in normal elderly and Alzheimer's disease (AD) patients. To date, special attention has been paid to sleep disturbance in the clinical course of AD insofar as the interaction of sleep disturbance with the pathogenesis of AD may impact the clinical course and cognitive function of $A D$ patients. This review covers the bidirectional relationship between sleep disturbance and AD pathogenesis; the associations between sleep disturbance and AD-specific neurotransmitters, brain structure, and aspects of sleep disturbance in each phase of $\mathrm{AD}$; and the effects of sleep disturbance on the cognitive functions of patients in each phase of $A D$. We consider several factors required to exactly interpret the results and suggest a direction for future studies on the role of sleep disturbance in $A D$.
\end{abstract}

KEY WORDS: Sleep; Alzheimer disease; Mild cognitive impairment; Aging; Amyloid beta-peptides; Cognition.

\section{INTRODUCTION}

Sleep disturbance is a frequent occurrence in the normal aging process, which involves deterioration in sleep quality, represented by increased sleep latency, difficulty with sleep maintenance, and early morning awakening and has been documented to include an increase in the prevalence of circadian sleep disturbance and sleep disordered breathing (SDB). ${ }^{1)}$

Sleep affects various domains of cognitive function, including attention and memory consolidation. ${ }^{2,3)}$ In addition, sleep disturbance is a known risk factor of cognitive dysfunction in elderly. ${ }^{4-6)}$ Furthermore, recent studies have reported that sleep disturbance deteriorates cognitive function and functional impairment by facilitating the pathogenesis of Alzheimer's disease (AD). ${ }^{7,8)}$ Reciprocally, lifestyle change and an atrophy of brain structure caused by the progression of $\mathrm{AD}$ have been found to accentuate sleep disturbance. ${ }^{9-12)}$ In this regard, many studies have suggested mechanisms by which sleep disturbance has a relationship with AD pathogenesis. ${ }^{13-15)}$

The pathogenesis of $\mathrm{AD}$ affects the entire course of $\mathrm{AD}$,

Received: September 13, 2016 / Revised: October 16, 2016 Accepted: October 17, 2016

Address for correspondence: Hyun Kook Lim, MD, PhD Department of Psychiatry, St. Vincent's Hospital, College of

Medicine, The Catholic University of Korea, 93 Jungbu-daero,

Paldal-gu, Suwon 16247, Korea

Tel: +82-31-249-8167, Fax: +82-31-248-6758

E-mail:drblues@catholic.ac.kr including preclinical dementia, minimal cognitive impairment (MCI), and advanced AD. ${ }^{16)}$ However, most existing studies separately examine sleep disturbance in each phase of $\mathrm{AD}$. Therefore, the existing research is limited in its understanding of sleep disturbance in differing aspects of the entirety of AD progression.

The authors of the current study reviewed the relationship between sleep disturbance and AD pathogenesis from multiple, integrated perspectives, including mechanisms by which sleep disturbance interacts with AD pathogenesis, aspects of sleep disturbance over the entire course of $\mathrm{AD}$, and the effects of sleep disturbance on cognitive functions over the entire course of $\mathrm{AD}$.

\section{RELATIONSHIP BETWEEN SLEEP DISTURBANCE AND AD PATHOGENESIS}

\section{Sleep Disturbance as a Risk Factor of $\mathrm{MCl}$ or $\mathrm{AD}$}

It is well documented that sleep disturbance is a risk factor of MCI or AD. In two community-based studies, poor sleep quality (investigated by self-reported questionnaire) was shown to increase the risk of dementia. ${ }^{17,18)}$ Furthermore, poor sleep quality has been reported to increase the risk of metabolic and cardiovascular diseases, which are known independent risk factors of $\mathrm{AD} .{ }^{19)}$

It is widely accepted that circadian rhythm disturbance is associated with increased risk of developing $\mathrm{AD}$. One study that measured circadian rhythms by actigraphy has

(a) This is an Open-Access article distributed under the terms of the Creative Commons Attribution Non-Commercial License (http://creativecommons.org/licenses/by-nc/4.0) which permits unrestricted non-commercial use, distribution, and reproduction in any medium, provided the original work is properly cited. 
shown that decreased amplitude of the sleep-wake cycles and delayed rhythms increase the odds of developing dementia in a community-based population. ${ }^{20)}$ Excessive daytime sleepiness (EDS) is a common symptom of circadian rhythm disturbance. According to a community-based longitudinal cohort study, subjects who suffer from EDS at baseline were twice as likely to be diagnosed with incident dementia. ${ }^{21)}$ In another study, disrupted daytime activity was shown to facilitate conversion to $\mathrm{MCI}$ or dementia. ${ }^{22}$ Sleep fragmentation is another common symptom of circadian rhythm disturbance and has been reported to increase the risk of incident $\mathrm{AD}$ in community dwelling, cognitively normal elderly. ${ }^{23)}$ Moreover, sleep consolidation has been reported to decrease the incidence of $\mathrm{AD}$ in community dwelling elderly. ${ }^{24)}$

It has been demonstrated that SDB increases the risk of developing dementia. ${ }^{25)}$ In one prospective study, subjects with SDB confirmed by polysomnography were shown to be prone to develop MCI or dementia with an $85 \%$ increased risk. ${ }^{26)}$ In that study, breathing had an adjusted odds ratio of 1.85 for the development of MCI or dementia in subjects. ${ }^{26)}$

In addition, cognitively normal elderly with the apolipoprotein epsilon 4 (APOE E4) allele reporting sleep disturbance have shown a risk level for developing MCI or dementia seven times as high as that of cognitively normal elderly without the APOE E4 allele reporting sleep disturbance. ${ }^{27)}$

Furthermore, in circadian rhythm disturbance, poorer rhythm measured by actigraphy has been associated with later stages of dementia. ${ }^{28)}$ There also is a relationship between the frequency of apnea and the severity of dementia in elderly with SDB. ${ }^{29)}$ It has been suggested that frontal-subcortical pathology associated with SDB could increase the risk of developing dementia. ${ }^{29)}$

\section{Effect of Sleep on AD Pathology}

Several studies have reported that sleep disturbance precipitates the accumulation of beta amyloid $(\mathrm{A} \beta)$ protein in brain. Poor sleep quality, measured by self-reporting, has been implicated in the accumulation of $A \beta$ measured by positron emission tomography (PET) scanning. ${ }^{30)}$ Among objective sleep parameters representing sleep quality, longer sleep latency has been shown to be related to the accumulation of $A \beta$ in the prefrontal region of the brain. ${ }^{31)}$ In addition, subjects with less adequate sleep, more sleep problems, and greater somnolence have greater $A \beta$ burdens measured by PET scanning in prefrontal and insular regions of the brain. ${ }^{31)}$ Sleep duration has also been shown to have a relationship with the accumulation of $A \beta$. Shorter sleep duration was previously associated with greater $A \beta$ burden measured by PET scanning in the precuneus, angular gyrus and frontal medial orbital cortex. ${ }^{32)}$ Most of these studies had a crossover design. Therefore, all of these results have limitations insofar as they only clarify the causal effects of sleep disturbance on AD pathology. Accordingly, a prospective study was conducted and found that improving sleep quality reduced the incidence of $\mathrm{AD}$ and neurofibrillary tangle density in cognitively normal elderly with the APOE E4 allele. ${ }^{24)}$ Furthermore, in amyloid precursor protein transgenic mice, chronic sleep deprivation promoted formation of amyloid plaque, while orexin receptor antagonists (which induce sleep) decreased formation of $A \beta$ plaque. ${ }^{7)}$ In addition, it has been suggested that circadian rhythm disturbance could facilitate the accumulation of $\mathrm{A} \beta$ by promoting molecular transcription, autophagy, and the formation of reactive oxygen species. ${ }^{33)}$ Moreover, one recent study assessed the effects of respiratory and non-respiratory sleep variables on the accumulation of $A \beta$ in MCI subjects and showed that respiratory variables, such as the apnea-hypopnea index (AHI) and an oxygen desaturation index, precipitated $\mathrm{A} \beta$ deposition. ${ }^{34)}$ Furthermore, SDB has been reported to be associated with $\mathrm{AD}$-specific cerebrospinal fluid (CSF) biomarkers in cognitively normal elderly. ${ }^{35}$

There are several suggested mechanisms that show how sleep disturbance could precipitate the accumulation of $A \beta$. One mechanism is that sleep disturbance inhibits the clearance of $A \beta$. One study measured the volume of brain interstitial space that is supposed to exchange and clear $\mathrm{A} \beta$ with CSF in mice by altering the sleep state. ${ }^{13)}$ The study found that the brain interstitial space was $60 \%$ larger in sleeping and anesthetized mice than in awake mice, and that level of amyloid beta was associated with time spent awake. $^{13)}$

Another proposed mechanism is that sleep disturbance increases synaptic activity and facilitates the accumulation of $A \beta$. Among the stages of sleep, the slow wave sleep stage (SWS) is the phase in which synaptic activity is most greatly decreased. ${ }^{36,37)}$ In this regard, decreased SWS induces increased synaptic activity. In addition, increased synaptic activity releases $A \beta$ into brain interstitial fluid. It has been documented that increased synaptic activity in specific regions is related to region-specific increases of $A \beta{ }^{14)}$ In particular, brain regions in the default mode network (DMN) are most active during quiet wakefulness and are known to be most prone to aggravation 
with $A \beta .^{38,39)}$ This DMN has been reported to be deactivated during SWS. ${ }^{40)}$ In this regard, sleep disturbance could decrease SWS, activate brain components of the DMN, and accelerate the accumulation of $A \beta$ in this region.

A third possible mechanism is that sleep disturbance impairs the response of the endoplasmic reticulum to cellular stress, leading to $\mathrm{A} \beta$ misfolding and accumulation. ${ }^{15)}$ Changes due to this response at the molecular level have been suggested to be common features in neurodegenerative diseases, including AD. ${ }^{41)}$ Indeed, aging enhances the adverse effects of sleep disturbance on promoting the accumulation of $A \beta$ through synergistic interaction with changes in the response at the molecular level. ${ }^{42}$

\section{Effect of AD Pathology on Sleep}

The accumulation of $A \beta$ could directly interfere with neuronal functions in brain regions that regulate sleep. ${ }^{43)} \mathrm{It}$ has been confirmed that $\mathrm{A} \beta$ accumulation measured by PET scanning disrupts SWS and memory consolidation in the elderly, and it has been assumed that $\mathrm{A} \beta$ accumulation affects the pathways that regulate the sleep-wake cycle. ${ }^{44)}$ Another study has reported that subjects with $A \beta$ confirmed by PET scanning lack a diurnal variation of $A \beta{ }^{45)}$ The design of these studies, however, was cross-sectional. To investigate the causative effects of AD pathology on sleep disturbance, studies with mutant mice have been conducted. Mutant mice that are prone to amyloid plaque deposition have shown a deficiency in the sleep-wake cycle and are shown to lack a diurnal variation of $A \beta$ after the formation of amyloid plaque. ${ }^{46)}$ Furthermore, active immunization to remove amyloid plaque normalizes the sleep-wake cycle and the diurnal variation of $A \beta$ in mutant mice. ${ }^{46)}$ Also, a study with APP/PS1 knock-in mice, a model of $\mathrm{AD}$, has indicated that mutant mice have a phase delay in the sleep-wake cycle in comparison to wild-type mice. ${ }^{47)}$ Another transgenic mice study, in which human-mutated amyloid and tau transgenes were inserted into animal subjects, has shown reduced sleep duration, shorter sleep bouts, and reduced amplitude in the sleep-wake cycle with a decline of multiple cognitive domains. ${ }^{48)}$

\section{Effects of Hypnotics on AD Pathology}

With the understanding that sleep affects AD pathology, hypnotics acting through $\gamma$-aminobutyric acid A (GABA A) receptor could be assumed to impact AD pathology and progression. Although there are few human studies regarding the efficacy of hypnotics on AD pathology and progression, several transgenic mice studies have observed the efficacy of GABA A agonists on AD pathology. GABA A agonists have been shown to reduce $\mathrm{A} \beta$ induced neurotoxicity in hippocampus and cortical neurons, to ameliorate neuronal maturation and neurogenesis, to decrease the deposition of $A \beta$ fibrils in the CA1 area of the hippocampus and to improve cognitive function in AD mouse model. ${ }^{49-54)}$ Moreover, these researches suggested that the stimulation of GABA A receptor might protect against $A D$ pathology by attenuating the $A \beta$ induced mitochondria dysfunction, enhancing glycogen synthase kinase 3 beta (GSK-3 $\beta$ ) pathway and balancing between excitatory and inhibitory systems underlying synaptic function. ${ }^{54-56)}$ However, there are other evidences of long term adverse effects of GABA A agonists and their relationship with increased risk of dementia. ${ }^{57}$

\section{Associations between Sleep Disturbance and Changes of Neurotransmitters in $A D$}

Changes in the neurotransmitters in $\mathrm{AD}$ have been documented to be associated with sleep disturbance. One change involves the cholinergic system. Cholinergic pathways are known to correlate with wake promotion and maintenance, participating in the ascending reticular activating system. ${ }^{58,59)}$ The cholinergic system also has a major role in modulating electroencephalogram (EEG) activation, which is representative of rapid eye movement (REM) sleep. ${ }^{60)}$ Due to vulnerability of cholinergic neurons in the nucleus basalis of Meynert to neurodegenerative stress, cholinergic dysfunction by $A \beta$ accumulation has been reported to induce REM deficits in MCI and AD populations. ${ }^{61)}$ Another neurotransmitter change involves the noradrenergic system. In AD, noradrenergic dysfunction in the brain stem is assumed to decrease REM sleep. ${ }^{62)}$ Research has shown that noradrenergic dysfunction in the pineal gland provokes the decrease of melatonin level in subjects with preclinical $\mathrm{AD}$ and $\mathrm{AD} .^{63)}$ In addition, melatonin regulates the biological clock and the sleep-wake cycle and is supposed to have neuroprotective characteristics. ${ }^{63,64)}$ Evidence indicating that melatonin is implicated in $\mathrm{AD}$ pathogenesis continues to accumulate. $\mathrm{AD}$ patients with homozygous APOE E4 alleles have lower melatonin level than those with heterozygous APOE E4 alleles. ${ }^{65)}$ Furthermore, there is a relationship between level of melatonin and the severity of sleep disturbance in subjects with dementia. ${ }^{66)}$ In addition, MCI patients treated with melatonin show better cognitive function and sleep quality than patients without melatonin supplement. ${ }^{67,68)}$ 


\section{Association between Sleep Disturbance and AD-specific Brain Structure}

There are several studies regarding the relationship between sleep disturbance and AD-specific brain structure. Among self-reported sleep parameters in cognitively healthy elderly, frequency of nocturnal awakening has been negatively correlated with the volume of gray matter in the insular region, known to be vulnerable to $\mathrm{AD}$ pathogenesis. $^{31)}$ Other studies have demonstrated that poor sleep is associated with a decrease in gray matter volume of the frontal cortex and hippocampus and an increased rate of atrophy in the frontal, temporal, and parietal regions of the brains of elderly subjects in community-dwelling populations. ${ }^{69,70)}$ Additionally, atrophy of brain regions vulnerable to $\mathrm{AD}$ pathogenesis, such as the medial prefrontal cortex and cholinergic structures in the forebrain, has been reported to compromise non-rapid eye movement (NREM) sleep and REM sleep, respectively., ${ }^{9,10)}$

\section{Bidirectional Relationship between Sleep Disturbance and $A D$ Pathogenesis}

Current research has provided evidence that the relationship between sleep disturbance and AD pathogenesis is bidirectional. Sleep disturbance appears to facilitate the progression of $\mathrm{AD}$ pathogenesis, including the accumulation of $A \beta$ and tau proteins through dysfunctional clearance of neurotoxins, increased synaptic activity, and impaired molecular response. Consequently, AD patho- genesis could compromise brain regions that modulate the sleep-wake cycle and affect neurotransmitters implicated in sleep processes. In this regard, sleep disturbance and $\mathrm{AD}$ pathogenesis are caught in a vicious cycle whereby sleep disturbance leads to increased AD pathogenesis, which in turn exacerbates sleep disturbance (Fig. 1).

\section{SLEEP IN NORMAL AGING}

\section{Changes in Sleep in Normal Aging}

Sleep structure changes with aging due to the reduction of SWS and a compensatory increase of the lighter sleep stage. ${ }^{1)}$ Changes in the REM sleep stage appear to be unremarkable in normal aging, but have a propensity to show a decrease in delta waves and an increase in fast waves. ${ }^{71,72)}$ Elderly people are prone to awaken less during REM sleep, but more during NREM sleep and are known to have fewer numbers of sleep spindles and K-complexes in NREM than young adults. ${ }^{73)}$ These changes in sleep with aging have been documented in nearly all people older than 60 years and to worsen in populations of elderly people with the APOE E4 allele. ${ }^{74)}$ In accordance with impaired sleep structure, sleep quality is also compromised due to aging. Sleep efficiency tends to be decreased, sleep fragmentation tends to be increased, and sleep phases are inclined to advance with aging. ${ }^{75)}$ Synchronization of circadian sleep disturbance is impaired with aging. ${ }^{68)}$ Among elderly people, $20-30 \%$ complains of EDS. ${ }^{76,77)}$ In addition, SDB is

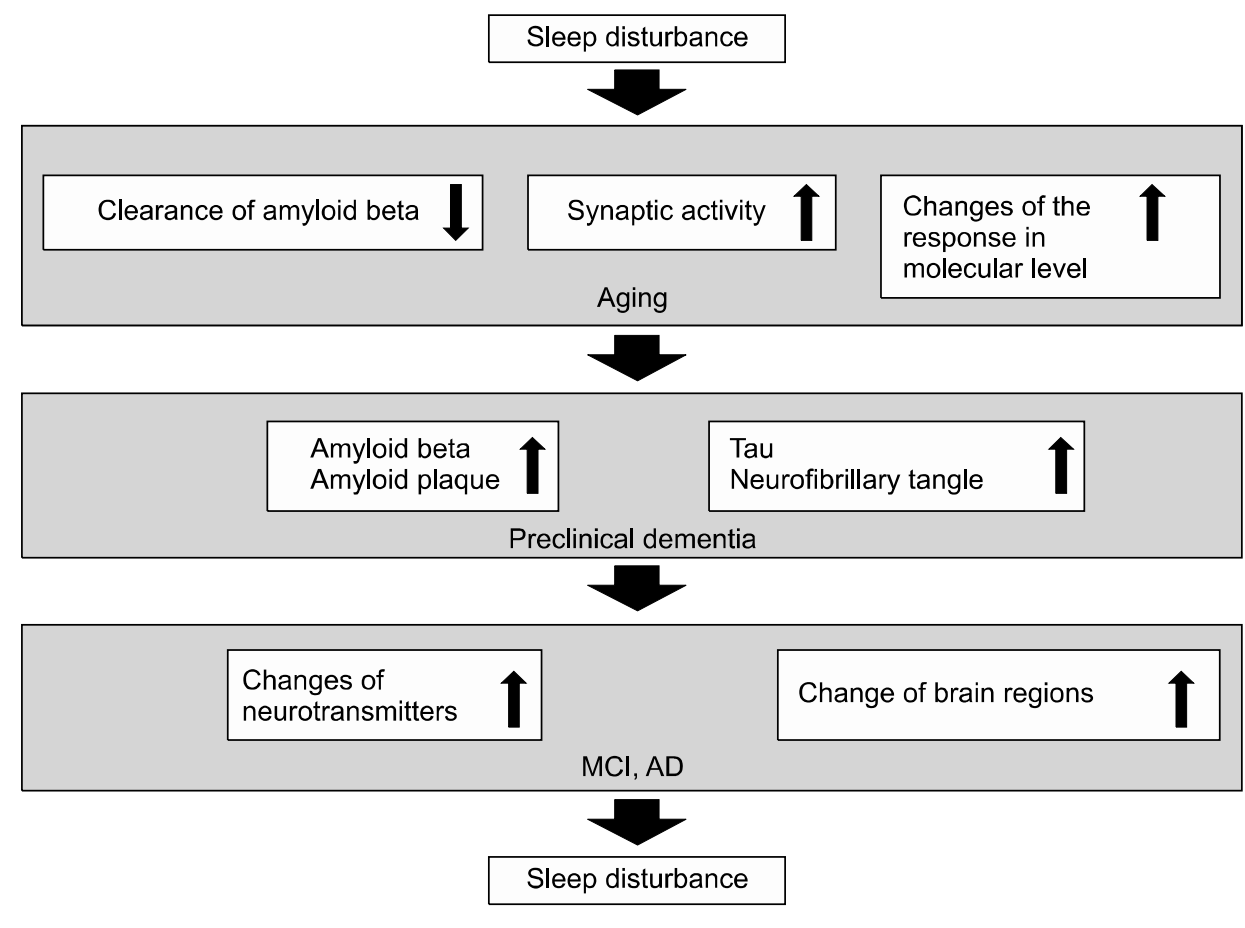

Fig. 1. Bidirectional relationship between sleep disturbance and $A D$ pathogenesis. $\mathrm{MCl}$, mild cognitive impairment; AD, Alzheimer's disease. 
another common symptom of sleep disturbance. Seventeen percent of elderly males and $9 \%$ of elderly females are estimated to suffer from moderate to severe SDB. ${ }^{78)}$ Moreover, a population of subjects with preclinical dementia with amyloid burden has been shown to have worse sleep quality than a population without amyloid burden, including reduced sleep efficiency and frequent napping, as estimated by actigraphy. ${ }^{79)}$

\section{Relationship between Sleep Disturbance and Cognitive Function in Normal Aging}

The disruption of sleep structure is known to have a correlation with cognitive function in normal elderly. Declarative memories are known to improve after SWS, but the relationship between memory function and SWS has been reported to be more attenuated in normal elderly than in younger adults. ${ }^{3,80)}$ An increased number of sleep spindles, which are components of stage 2 sleep, have been reported to be associated with verbal memory retention. $^{81)}$

During the REM sleep stage, newly encoded memories appear to consolidate. In a cohort study with cognitively normal elderly, REM sleep latency and REM density showed a correlation with decline of cognitive function. ${ }^{2,82)}$

There has been a controversy regarding the relationship between sleep quality and cognitive function in normal elderly. Many studies have observed that poor sleep quality by subjective, objective measurement is associated with decline of cognitive function including memory retention, attention and executive function. ${ }^{4-6,83,84)}$ Convertsely, improved sleep quality attenuates the adverse effects of the APOE E4 allele, a high-risk genotype, on cognitive function. ${ }^{24)}$ In contrast to these findings, it also has been reported in certain other prospective and crossover studies that poor sleep quality has no significant association with cognitive function. ${ }^{25,85,86)}$

Some controversy also exists concerning the relationship between sleep duration and cognitive function. In studies with subjective and objective measurements of sleep duration, it has been shown that longer sleep duration impairs cognitive function. ${ }^{87-90)}$ There are other reports that both short and long sleep durations worsen cognitive function, indicating a U-shaped pattern of the relationship between cognitive function and sleep duration. ${ }^{25}$ Three prospective studies have demonstrated that short and long sleep durations measured by self-reported questionnaires precipitate cognitive dysfunction in elderly subjects. ${ }^{91-93)}$ However, some researchers have reported that sleep duration has no correlation with cognitive function. Sleep duration measured by actigraphy has been reported to have no association with cognitive function estimated in a cross-sectional study using the Mini-Mental State Examination (MMSE) and a trail-making test. ${ }^{6,94)}$ Another study has concentrated on the effects of age on the relationship between sleep duration and cognitive function. In a group of patients 50 to 64 years of age, both short and long sleep durations were associated with a decline of cognitive function. ${ }^{95)}$ However, in a group of patients over 65 years of age, this association remained significant only in those with a long sleep duration. ${ }^{95}$

Sleep fragmentation evaluated by actigraphy has been demonstrated to accentuate cognitive dysfunction and to accelerate the rate of decline in cognitive function. ${ }^{6,89,96)}$ In a meta-analysis, sleep deprivation by sleep fragmentation was also associated with cognitive decline, including decline of memory and executive function. ${ }^{97)}$ In addition, sleep consolidation has been shown to lower the rate of cognitive decline in community-dwelling elderly with the APOE E4 allele. ${ }^{23)}$ EDS has been reported to have a correlation with cognitive decline in community-dwelling elderly. ${ }^{83,85,98)}$ In an animal study, circadian rhythm disruption induced by frequent phase shifting was correlated with decrements of cognitive function, such as learning and memory. ${ }^{99)}$

Evidence continues to accumulate indicating that SDB is associated with cognitive decline in normal elderly. In a prospective study, mild to moderate SDB was associated with cognitive decline evaluated by MMSE in community-dwelling elderly. ${ }^{100)}$ Additionally, SDB parameters encompassing the AHI and oxygen saturation were correlated with decrements of global cognitive function. ${ }^{101)}$ Furthermore, this observation was particularly remarkable in a population of subjects with the APOE E4 allele. ${ }^{101)}$ There is another report that the APOE E4 allele affects the relationship between SDB and cognitive decline. ${ }^{95)}$ According to that research, higher AHI score aggravated memory function only in subjects with the APOE E4 allele. ${ }^{102)}$ According to that research, higher AHI score aggravated memory function only in subjects with the APOE E4 allele. ${ }^{102)}$

There is some disagreement concerning the relationship between SDB and cognitive decline. Two cross-sectional studies and one prospective study with normal elderly participants have shown no significant association between AHI and cognitive decline. ${ }^{89,103)}$ 


\section{SLEEP IN MCI}

\section{Changes in Sleep in $\mathrm{MCl}$}

Prevalence of sleep disturbance in MCI subjects has been documented to range from $8.8 \%$ to $45.5 \%{ }^{104,105)}$ In addition, SDB and sleep behavior disorders appear more frequently in MCI patients than in normal patients. ${ }^{106)}$ In one prospective study, MCI subjects who converted to AD had shown no differences in parameters of sleep disturbance than MCI subjects who remained stable. ${ }^{107)}$

Changes in sleep structure in amnestic MCI patients have been demonstrated in respective sleep stages. In the NREM stage of sleep, the duration of SWS is more decreased in MCI patients than in cognitively normal elderly. ${ }^{108)}$ In addition, the power of both delta and theta waves in the NREM sleep stage were found to be more reduced in amnestic MCI patients than in cognitively normal elderly, and fast sleep spindles in the NREM sleep stage have been reported to be more reduced in amnestic MCI patients than in normal elderly. ${ }^{108)}$ And fast sleep spindles in NREM sleep stage has been reported to be more reduced in amnestic MCI patients than in normal elderly. The duration of REM has been shown to be remarkably reduced in MCI patients with the APOE E4 allele. ${ }^{109)}$ In addition, it has been documented that theta waves are diminished during the REM sleep stage in MCI patients. $^{108)}$

\section{Relationship between Sleep Disturbance and Cognitive Function in $\mathrm{MCl}$}

In amnestic MCI patients, memory functions, such as recall and recognition, have been shown to be improved after sleep consolidation, but were still lower than those in a control group. ${ }^{110)}$ It has been observed that the impairment of memory functions in MCI patients is associated with reductions in delta and theta power measured by polysomnography. ${ }^{108)}$ That research also showed that greater variability across nights of sleep predicts an impairment of memory recall. ${ }^{108)}$ In non-amnestic MCI (naMCI) patients, characteristics of sleep fragmentation are associated with cognitive dysfunction. ${ }^{111)}$ An increased number of wake arousals after sleep onset (WASO) has been shown to be correlated with an impairment of nonverbal learning, and increased duration of WASO was associated with impairment of several domains of cognitive function, including attention, response inhibition, concept forming, and problem solving in naMCI patients. ${ }^{111)}$ In MCI patients with the APOE E4 allele, increased duration of REM sleep improves the performance of immediate recall. ${ }^{109)}$

\section{SLEEP IN AD}

\section{Changes in Sleep in AD}

The prevalence of sleep disturbance in $\mathrm{AD}$ patients has been reported to range from $25 \%$ to $60 \%$ according to the categorization of sleep disturbance. ${ }^{112,113)} \mathrm{AD}$ patients complain of subjective sleep problems more frequently than cognitively normal elderly $(18.3 \%$ vs. $27.6 \%){ }^{114)}$ The prevalence of SDB was shown to be as high as $60 \%$ in AD patients. ${ }^{113)}$ The prevalence of circadian sleep disturbance has been estimated to be $25 \%$ in AD patients. ${ }^{115}$ ) In addition, as many as $25 \%$ to $50 \%$ of $\mathrm{AD}$ patients have been reported to suffer from a nocturnal restlessness known as "sundowning.","112)

Changes in sleep structure in AD patients are perceived as an exaggeration of the changes in sleep due to normal aging and are understood to be aggravated with the progression of the disease. AD patients show reduced sleep efficiency, sleep fragmentation, and decreased total sleep time. ${ }^{62)}$ Furthermore, stage 1 sleep is increased, sleep spindles are decreased, and SWS is decreased in AD patients. ${ }^{116,117)}$ Several studies have reported decreased REM sleep in AD patients, which is associated with emotional and behavioral changes. ${ }^{118-121)}$ Furthermore, EEG slowing in the REM sleep of AD patients has been observed in frontal, parietal, and temporal brain regions. ${ }^{122)}$ In contrast, another study has observed an unchanged total number of REM sleep episodes and REM sleep latency in AD patients. ${ }^{123)}$

Circadian sleep disturbance is also represented in AD patients. AD patients are known to frequently experience sleep fragmentation and EDS. ${ }^{62,124)}$ In advanced stages of $\mathrm{AD}$, the amplitude of circadian rhythms is reduced, and the phase of circadian rhythms is delayed. ${ }^{125)}$ These changes have been documented to be aggravated as a function of the severity of dementia. ${ }^{125)}$

\section{A Relationship between Sleep Disturbance and Cognitive Function in $A D$}

Several studies have reported that changes in sleep structure are associated with cognitive function in AD patients. It has been suggested that decreased sleep spindles, a feature of sleep changes in $\mathrm{AD}$, are implicated in the pathway of memory consolidation between the hippocampus and neocortical areas of the brain. ${ }^{3)}$ In mild to moderate $\mathrm{AD}$ patients following a challenge with donepezil, increased REM sleep has been associated with improved cognitive function. ${ }^{126)}$ In addition, sleep duration has also been reported to affect cognitive function in $\mathrm{AD}$ 
patients. ${ }^{114)}$ In a crossover study in AD patients, it has been reported that shorter sleep duration was correlated with better cognitive function and longer sleep duration was associated with poor cognition and function. ${ }^{114)}$

In mild to moderate $\mathrm{AD}, \mathrm{EDS}$ is correlated with global cognitive dysfunction including psychomotor and memory impairment. ${ }^{119)}$ In other research, aberrations of sleep parameters associated with cognitive dysfunction have been reported to have worsened in $\mathrm{AD}$ patients without the APOE E4 allele than in AD patients with the APOE E4 allele. ${ }^{127)}$ The authors of that study concluded that further studies are needed to elucidate the relationships among APOE E4 allele, sleep parameters, and cognitive function in terms of changes in hormones and brain regions of AD patients. $^{127)}$

\section{CONCLUSION}

The current article reviews numerous studies that support the bidirectional relationship between sleep disturbance and $\mathrm{AD}$ pathogenesis. Sleep disturbance affects $\mathrm{AD}$ pathogenesis over the entire course of $\mathrm{AD}$ from the preclinical phase to advanced phases of AD. Consequently, a decline of cognitive function is induced by accentuated $\mathrm{AD}$ pathogenesis. Inversely, an aggravated $\mathrm{AD}$ pathogenesis deteriorates sleep, forming a vicious cycle throughout the course of AD.

Current methods of treatment for AD do not target modification of $\mathrm{AD}$ pathogenesis, but instead work to slow the rate of the disease. The reality, however, is that $\mathrm{AD}$ pathogenesis has already progressed for 10 to 20 years before $\mathrm{AD}$ patients reveal symptoms of cognitive dysfunction and functional impairment. ${ }^{128)}$ Accordingly, it is important to modulate the modifiable risk factors of $\mathrm{AD}$ in the preclinical phase for the prevention of $\mathrm{AD} .^{129,130)}$ Delaying symptom onset by as little as one year could reduce $\mathrm{AD}$ prevalence by more than nine million cases over the next 40 years. ${ }^{131)}$ Among variable modifiable risk factors, with the understanding that sleep disturbance directly impacts $\mathrm{AD}$ pathogenesis, the treatment of sleep disturbance has a great deal of importance.

The studies presented here need careful interpretation with regard to measurements of sleep and cognitive function, study design, and exogenous factors. There are subjective and objective ways to measure sleep disturbance. It is recognized that subjective measurement of sleep disturbance in $\mathrm{AD}$ patients does not exactly reflect an objective measurement of sleep disturbance in the sample. ${ }^{132)}$ Moreover, some studies use a tool for screening cognitive dysfunction, such as MMSE, while other studies use a tool for confirming cognitive dysfunction, such as the cognitive assessment battery.

In the analysis herein, the number of cross-sectional studies reviewed was greater than the number of prospective studies. According to the designs of the pertinent studies, the relationship between variables could be associative or causal.

Exogenous factors could affect the relationship between sleep disturbance and AD pathogenesis, which causes cognitive dysfunction. It has been reported that several factors, including cognitive reserve, depression, cardiovascular factors, external zeitgebers, and neurosensory dysfunction, could affect sleep disturbance and AD pathogenesis. ${ }^{133)}$ Some studies adjust for exogenous factors, while other studies do not consider these factors. Therefore, the results of the relationships between sleep disturbance, $\mathrm{AD}$ pathogenesis, and cognitive dysfunction should be interpreted with caution by considering relevant factors. Furthermore, future studies will be required to ascertain the role of sleep disturbance in the understanding and treatment of $\mathrm{AD}$ by focusing on the preclinical phase of $\mathrm{AD}$, undertaking more prospective studies with more accurate measurements of sleep and cognitive function, and adjusting for known exogenous factors.

\section{- Acknowledgments}

This research was supported by Basic Science Research Program through the National Research Foundation of Korea (NRF) funded by the Ministry of Science, ICT \& Future Planning (NRF-2015R1C1A1A02036578).

\section{REFERENCES}

1. Cooke JR, Ancoli-Israel S. Normal and abnormal sleep in the elderly. Handb Clin Neurol 2011;98:653-665.

2. Karni A, Tanne D, Rubenstein BS, Askenasy JJ, Sagi D. Dependence on REM sleep of overnight improvement of a perceptual skill. Science 1994;265:679-682.

3. Born J, Rasch B, Gais S. Sleep to remember. Neuroscientist 2006;12:410-424.

4. Jelicic M, Bosma H, Ponds RW, Van Boxtel MP, Houx PJ, Jolles J. Subjective sleep problems in later life as predictors of cognitive decline. Report from the Maastricht Ageing Study (MAAS). Int J Geriatr Psychiatry 2002;17: 73-77.

5. Potvin O, Lorrain D, Forget H, Dubé M, Grenier S, Préville M, et al. Sleep quality and 1-year incident cognitive impairment in community-dwelling older adults. Sleep 2012;35:491-499.

6. Blackwell T, Yaffe K, Ancoli-Israel S, Schneider JL, Cauley JA, Hillier TA, et al. Poor sleep is associated with impaired cognitive function in older women: the study of osteoporotic fractures. J Gerontol A Biol Sci Med Sci 2006;61:405-410. 
7. Kang JE, Lim MM, Bateman RJ, Lee JJ, Smyth LP, Cirrito $\mathrm{JR}$, et al. Amyloid-beta dynamics are regulated by orexin and the sleep-wake cycle. Science 2009;326:1005-1007.

8. Ju YE, Lucey BP, Holtzman DM. Sleep and Alzheimer disease pathology--a bidirectional relationship. Nat Rev Neurol 2014;10:115-119.

9. Mander BA, Rao V, Lu B, Saletin JM, Lindquist JR, Ancoli-Israel S, et al. Prefrontal atrophy, disrupted NREM slow waves and impaired hippocampal-dependent memory in aging. Nat Neurosci 2013;16:357-364.

10. Montplaisir J, Petit D, Gauthier S, Gaudreau H, Décary A. Sleep disturbances and eeg slowing in alzheimer's disease. Sleep Res Online 1998;1:147-151.

11. Landau SM, Marks SM, Mormino EC, Rabinovici GD, Oh $\mathrm{H}$, O'Neil JP, et al. Association of lifetime cognitive engagement and low $\beta$-amyloid deposition. Arch Neurol 2012;69:623-629.

12. Liang KY, Mintun MA, Fagan AM, Goate AM, Bugg JM, Holtzman DM, et al. Exercise and Alzheimer's disease biomarkers in cognitively normal older adults. Ann Neurol 2010;68:311-318.

13. Xie L, Kang H, Xu Q, Chen MJ, Liao Y, Thiyagarajan M, et al. Sleep drives metabolite clearance from the adult brain. Science 2013;342:373-377.

14. Cirrito JR, Yamada KA, Finn MB, Sloviter RS, Bales KR, May PC, et al. Synaptic activity regulates interstitial fluid amyloid-beta levels in vivo. Neuron 2005;48:913-922.

15. Naidoo N, Ferber M, Master M, Zhu Y, Pack AI. Aging impairs the unfolded protein response to sleep deprivation and leads to proapoptotic signaling. J Neurosci 2008;28: 6539-6548.

16. Jack CR Jr, Knopman DS, Jagust WJ, Petersen RC, Weiner MW, Aisen PS, et al. Tracking pathophysiological processes in Alzheimer's disease: an updated hypothetical model of dynamic biomarkers. Lancet Neurol 2013;12:207-216.

17. Elwood PC, Bayer AJ, Fish M, Pickering J, Mitchell C, Gallacher JE. Sleep disturbance and daytime sleepiness predict vascular dementia. J Epidemiol Community Health 2011;65:820-824.

18. Sterniczuk R, Theou O, Rusak B, Rockwood K. Sleep disturbance is associated with incident dementia and mortality. Curr Alzheimer Res 2013;10:767-775.

19. Landry GJ, Liu-Ambrose T. Buying time: a rationale for examining the use of circadian rhythm and sleep interventions to delay progression of mild cognitive impairment to Alzheimer's disease. Front Aging Neurosci 2014;6:325.

20. Tranah GJ, Blackwell T, Stone KL, Ancoli-Israel S, Paudel ML, Ensrud KE, et al. Circadian activity rhythms and risk of incident dementia and mild cognitive impairment in older women. Ann Neurol 2011;70:722-732.

21. Foley D, Monjan A, Masaki K, Ross W, Havlik R, White $\mathrm{L}$, et al. Daytime sleepiness is associated with 3-year incident dementia and cognitive decline in older JapaneseAmerican men. J Am Geriatr Soc 2001;49:1628-1632.

22. Schlosser Covell GE, Dhawan PS, Lee Iannotti JK, Hoffman-Snyder CR, Wellik KE, Caselli RJ, et al. Disrupted daytime activity and altered sleep-wake patterns may predict transition to mild cognitive impairment or dementia: a critically appraised topic. Neurologist 2012; 18:426-429.

23. Lim AS, Kowgier M, Yu L, Buchman AS, Bennett DA. Sleep fragmentation and the risk of incident Alzheimer's disease and cognitive decline in older persons. Sleep 2013;36:1027-1032.

24. Lim AS, Yu L, Kowgier M, Schneider JA, Buchman AS,
Bennett DA. Modification of the relationship of the apolipoprotein $E \& 4$ allele to the risk of Alzheimer disease and neurofibrillary tangle density by sleep. JAMA Neurol 2013;70:1544-1551.

25. Tworoger SS, Lee S, Schernhammer ES, Grodstein F. The association of self-reported sleep duration, difficulty sleeping, and snoring with cognitive function in older women. Alzheimer Dis Assoc Disord 2006;20:41-48.

26. Yaffe K, Laffan AM, Harrison SL, Redline S, Spira AP, Ensrud KE, et al. Sleep-disordered breathing, hypoxia, and risk of mild cognitive impairment and dementia in older women. JAMA 2011;306:613-619.

27. Burke SL, Maramaldi P, Cadet T, Kukull W. Associations between depression, sleep disturbance, and apolipoprotein $E$ in the development of Alzheimer's disease: dementia. Int Psychogeriatr 2016;28:1409-1424.

28. Hoch CC, Reynolds CF 3rd, Kupfer DJ, Houck PR, Berman SR, Stack JA. Sleep-disordered breathing in normal and pathologic aging. J Clin Psychiatry 1986;47: 499-503.

29. Kim SJ, Lee JH, Lee DY, Jhoo JH, Woo JI. Neurocognitive dysfunction associated with sleep quality and sleep apnea in patients with mild cognitive impairment. Am J Geriatr Psychiatry 2011;19:374-381.

30. Spira AP, Gamaldo AA, An Y, Wu MN, Simonsick EM, Bilgel $\mathrm{M}$, et al. Self-reported sleep and $\beta$-amyloid deposition in community-dwelling older adults. JAMA Neurol 2013;70:1537-1543.

31. Branger P, Arenaza-Urquijo EM, Tomadesso C, Mézenge $\mathrm{F}$, André C, de Flores R, et al. Relationships between sleep quality and brain volume, metabolism, and amyloid deposition in late adulthood. Neurobiol Aging 2016;41: 107-114.

32. Sprecher KE, Bendlin BB, Racine AM, Okonkwo OC, Christian BT, Koscik RL, et al. Amyloid burden is associated with self-reported sleep in nondemented late middle-aged adults. Neurobiol Aging 2015;36:2568-2576.

33. Hastings MH, Goedert M. Circadian clocks and neurodegenerative diseases: time to aggregate? Curr Opin Neurobiol 2013;23:880-887.

34. Spira AP, Yager C, Brandt J, Smith GS, Zhou Y, Mathur $\mathrm{A}$, et al. Objectively measured sleep and $\beta$-amyloid burden in older adults: A pilot study. SAGE Open Med 2014;2: 2050312114546520.

35. Osorio RS, Ayappa I, Mantua J, Gumb T, Varga A, Mooney AM, et al. Interaction between sleep-disordered breathing and apolipoprotein E genotype on cerebrospinal fluid biomarkers for Alzheimer's disease in cognitively normal elderly individuals. Neurobiol Aging 2014;35: 1318-1324.

36. Maquet P, Dive D, Salmon E, Sadzot B, Franco G, Poirrier $\mathrm{R}$, et al. Cerebral glucose utilization during sleep-wake cycle in man determined by positron emission tomography and [18F]2-fluoro-2-deoxy-D-glucose method. Brain Res 1990;513:136-143.

37. Dang-Vu TT, Schabus M, Desseilles M, Sterpenich V, Bonjean M, Maquet P. Functional neuroimaging insights into the physiology of human sleep. Sleep 2010;33:15891603.

38. Raichle ME, MacLeod AM, Snyder AZ, Powers WJ, Gusnard DA, Shulman GL. A default mode of brain function. Proc Natl Acad Sci U S A 2001;98:676-682.

39. Jagust WJ, Mormino EC. Lifespan brain activity, B-amyloid, and Alzheimer's disease. Trends Cogn Sci 2011;15:520-526. 
40. Sämann PG, Wehrle R, Hoehn D, Spoormaker VI, Peters $\mathrm{H}$, Tully $\mathrm{C}$, et al. Development of the brain's default mode network from wakefulness to slow wave sleep. Cereb Cortex 2011;21:2082-2093.

41. Lindholm D, Wootz H, Korhonen L. ER stress and neurodegenerative diseases. Cell Death Differ 2006;13: 385-392.

42. Naidoo N. Cellular stress/the unfolded protein response: relevance to sleep and sleep disorders. Sleep Med Rev 2009;13:195-204.

43. Braak H, Braak E. Neuropathological stageing of Alzheimer-related changes. Acta Neuropathol 1991;82: 239-259.

44. Mander BA, Marks SM, Vogel JW, Rao V, Lu B, Saletin $\mathrm{JM}$, et al. $\beta$-amyloid disrupts human NREM slow waves and related hippocampus-dependent memory consolidation. Nat Neurosci 2015;18:1051-1057.

45. Huang Y, Potter R, Sigurdson W, Santacruz A, Shih S, Ju $\mathrm{YE}$, et al. Effects of age and amyloid deposition on $A \beta$ dynamics in the human central nervous system. Arch Neurol 2012;69:51-58.

46. Roh JH, Huang Y, Bero AW, Kasten T, Stewart FR, Bateman RJ, et al. Disruption of the sleep-wake cycle and diurnal fluctuation of $\beta$-amyloid in mice with Alzheimer's disease pathology. Sci Transl Med 2012;4:150ral22.

47. Duncan MJ, Smith JT, Franklin KM, Beckett TL, Murphy MP, St Clair DK, et al. Effects of aging and genotype on circadian rhythms, sleep, and clock gene expression in APPXPS1 knock-in mice, a model for Alzheimer's disease. Exp Neurol 2012;236:249-258.

48. Platt B, Drever B, Koss D, Stoppelkamp S, Jyoti A, Plano $\mathrm{A}$, et al. Abnormal cognition, sleep, EEG and brain metabolism in a novel knock-in Alzheimer mouse, PLB1. PLoS One 2011;6:e27068.

49. Gu Z, Zhong P, Yan Z. Activation of muscarinic receptors inhibits beta-amyloid peptide-induced signaling in cortical slices. J Biol Chem 2003;278:17546-17556.

50. Louzada PR, Paula Lima AC, Mendonca-Silva DL, Noël F, De Mello FG, Ferreira ST. Taurine prevents the neurotoxicity of beta-amyloid and glutamate receptor agonists: activation of GABA receptors and possible implications for Alzheimer's disease and other neurological disorders. FASEB J 2004;18:511-518.

51. Paula-Lima AC, Louzada PR, De Mello FG, Ferreira ST. Neuroprotection against Abeta and glutamate toxicity by melatonin: are GABA receptors involved? Neurotox Res 2003;5:323-327.

52. Li G, Bien-Ly N, Andrews-Zwilling Y, Xu Q, Bernardo $\mathrm{A}$, Ring $\mathrm{K}$, et al. GABAergic interneuron dysfunction impairs hippocampal neurogenesis in adult apolipoprotein E4 knockin mice. Cell Stem Cell 2009;5:634-645.

53. Quiroga C, Chaparro RE, Karlnoski R, Erasso D, Gordon $\mathrm{M}$, Morgan $\mathrm{D}$, et al. Effects of repetitive exposure to anesthetics and analgesics in the Tg2576 mouse Alzheimer's model. Neurotox Res 2014;26:414-421.

54. Shao H, Zhang Y, Dong Y, Yu B, Xia W, Xie Z. Chronic treatment with anesthetic propofol improves cognitive function and attenuates caspase activation in both aged and Alzheimer's disease transgenic mice. J Alzheimers Dis 2014;41:499-513.

55. Zhang R, Xu J, Liu YY, Zuo PP, Yang N, Ji C, et al. Propofol may protect PC12 cells from $\beta$-amyloid $25-35$ induced apoptosis through the GSK-3 $\beta$ signaling pathway. Chin Med J (Engl) 2013;126:1884-1889.

56. Nava-Mesa MO, Jiménez-Díaz L, Yajeya J, Navarro-Lopez
JD. GABAergic neurotransmission and new strategies of neuromodulation to compensate synaptic dysfunction in early stages of Alzheimer's disease. Front Cell Neurosci 2014;8:167.

57. Lanctôt KL, Herrmann N, Mazzotta $P$, Khan LR, Ingber N. GABAergic function in Alzheimer's disease: evidence for dysfunction and potential as a therapeutic target for the treatment of behavioural and psychological symptoms of dementia. Can J Psychiatry 2004;49:439-453.

58. Jones BE. Activity, modulation and role of basal forebrain cholinergic neurons innervating the cerebral cortex. Prog Brain Res 2004;145:157-169.

59. Steriade M. Acetylcholine systems and rhythmic activities during the waking--sleep cycle. Prog Brain Res 2004; 145:179-196.

60. Berntson GG, Shafi R, Sarter M. Specific contributions of the basal forebrain corticopetal cholinergic system to electroencephalographic activity and sleep/waking behaviour. Eur $J$ Neurosci 2002;16:2453-2461.

61. Whitehouse PJ, Price DL, Clark AW, Coyle JT, DeLong MR. Alzheimer disease: evidence for selective loss of cholinergic neurons in the nucleus basalis. Ann Neurol 1981;10:122-126.

62. Avidan AY. Sleep and neurologic problems in the elderly. Sleep Med Clin 2006;1:273-292.

63. Wu YH, Swaab DF. Disturbance and strategies for reactivation of the circadian rhythm system in aging and Alzheimer's disease. Sleep Med 2007;8:623-636.

64. Roth HL. Dementia and sleep. Neurol Clin 2012;30:12131248.

65. Liu RY, Zhou JN, van Heerikhuize J, Hofman MA, Swaab DF. Decreased melatonin levels in postmortem cerebrospinal fluid in relation to aging, Alzheimer's disease, and apolipoprotein E-epsilon4/4 genotype. J Clin Endocrinol Metab 1999;84:323-327.

66. Mishima K, Tozawa T, Satoh K, Matsumoto Y, Hishikawa $\mathrm{Y}$, Okawa M. Melatonin secretion rhythm disorders in patients with senile dementia of Alzheimer's type with disturbed sleep-waking. Biol Psychiatry 1999;45:417-421.

67. Furio AM, Brusco LI, Cardinali DP. Possible therapeutic value of melatonin in mild cognitive impairment: a retrospective study. J Pineal Res 2007;43:404-409.

68. Cardinali DP, Vigo DE, Olivar N, Vidal MF, Furio AM, Brusco LI. Therapeutic application of melatonin in mild cognitive impairment. Am J Neurodegener Dis 2012;1:280291.

69. Elcombe EL, Lagopoulos J, Duffy SL, Lewis SJ, Norrie $\mathrm{L}$, Hickie IB, et al. Hippocampal volume in older adults at risk of cognitive decline: the role of sleep, vascular risk, and depression. J Alzheimers Dis 2015;44:1279-1290.

70. Sexton CE, Storsve AB, Walhovd KB, Johansen-Berg H, Fjell AM. Poor sleep quality is associated with increased cortical atrophy in community-dwelling adults. Neurology 2014;83:967-973.

71. Van Cauter E, Leproult R, Plat L. Age-related changes in slow wave sleep and REM sleep and relationship with growth hormone and cortisol levels in healthy men. JAMA 2000;284:861-868.

72. Luca G, Haba Rubio J, Andries D, Tobback N, Vollenweider P, Waeber G, et al. Age and gender variations of sleep in subjects without sleep disorders. Ann Med 2015;47:482-491.

73. Pace-Schott EF, Spencer RM. Age-related changes in the cognitive function of sleep. Prog Brain Res 2011;191: 75-89. 
74. Redline S, Kirchner HL, Quan SF, Gottlieb DJ, Kapur V, Newman A. The effects of age, sex, ethnicity, and sleep-disordered breathing on sleep architecture. Arch Intern Med 2004;164:406-418.

75. Geib LTC, Cataldo Neto A, Wainberg R, Nunes ML. Sleep and aging. Revista de Psiquiatria do Rio Grande do Sul 2003;25:453-465.

76. Young TB. Epidemiology of daytime sleepiness: definitions, symptomatology, and prevalence. J Clin Psychiatry 2004;65 Suppl 16:12-16.

77. Slater G, Steier J. Excessive daytime sleepiness in sleep disorders. J Thorac Dis 2012;4:608-616.

78. Peppard PE, Young T, Barnet JH, Palta M, Hagen EW, Hla KM. Increased prevalence of sleep-disordered breathing in adults. Am J Epidemiol 2013;177:1006-1014.

79. Ju YE, McLeland JS, Toedebusch CD, Xiong C, Fagan AM, Duntley SP, et al. Sleep quality and preclinical Alzheimer disease. JAMA Neurol 2013;70:587-593.

80. Scullin MK. Sleep, memory, and aging: the link between slow-wave sleep and episodic memory changes from younger to older adults. Psychol Aging 2013;28:105-114.

81. Clemens Z, Fabó D, Halász P. Overnight verbal memory retention correlates with the number of sleep spindles. Neuroscience 2005;132:529-535.

82. Spiegel R, Herzog A, Köberle S. Polygraphic sleep criteria as predictors of successful aging: an exploratory longitudinal study. Biol Psychiatry 1999;45:435-442.

83. Keage HA, Banks S, Yang KL, Morgan K, Brayne C, Matthews FE. What sleep characteristics predict cognitive decline in the elderly? Sleep Med 2012;13:886-892.

84. Nebes RD, Buysse DJ, Halligan EM, Houck PR, Monk TH. Self-reported sleep quality predicts poor cognitive performance in healthy older adults. J Gerontol B Psychol Sci Soc Sci 2009;64:180-187.

85. Jaussent I, Bouyer J, Ancelin ML, Berr C, Foubert-Samier A, Ritchie $\mathrm{K}$, et al. Excessive sleepiness is predictive of cognitive decline in the elderly. Sleep 2012;35:1201-1207.

86. Merlino G, Piani A, Gigli GL, Cancelli I, Rinaldi A, Baroselli A, et al. Daytime sleepiness is associated with dementia and cognitive decline in older Italian adults: a population-based study. Sleep Med 2010;11:372-377.

87. Faubel R, López-García E, Guallar-Castillón P, Graciani A, Banegas JR, Rodríguez-Artalejo F. Usual sleep duration and cognitive function in older adults in Spain. J Sleep Res 2009; 18:427-435.

88. Ramos AR, Dong C, Elkind MS, Boden-Albala B, Sacco RL, Rundek T, et al. Association between sleep duration and the mini-mental score: the Northern Manhattan study. $J$ Clin Sleep Med 2013;9:669-673.

89. Blackwell T, Yaffe K, Ancoli-Israel S, Redline S, Ensrud $\mathrm{KE}$, Stefanick ML, et al. Association of sleep characteristics and cognition in older community-dwelling men: the MrOS sleep study. Sleep 2011;34:1347-1356.

90. Schmutte T, Harris S, Levin R, Zweig R, Katz M, Lipton $\mathrm{R}$. The relation between cognitive functioning and self-reported sleep complaints in nondemented older adults: results from the Bronx aging study. Behav Sleep Med 2007;5:39-56.

91. Ferrie JE, Shipley MJ, Akbaraly TN, Marmot MG, Kivimäki M, Singh-Manoux A. Change in sleep duration and cognitive function: findings from the Whitehall II Study. Sleep 2011;34:565-573.

92. Devore EE, Grodstein F, Duffy JF, Stampfer MJ, Czeisler CA, Schernhammer ES. Sleep duration in midlife and later life in relation to cognition. J Am Geriatr Soc 2014;62:
1073-1081

93. Virta JJ, Heikkilä K, Perola M, Koskenvuo M, Räihä I, Rinne JO, et al. Midlife sleep characteristics associated with late life cognitive function. Sleep 2013;36:1533-1541, $1541 A$.

94. Spencer RM, Gouw AM, Ivry RB. Age-related decline of sleep-dependent consolidation. Learn Mem 2007;14:480-484.

95. Miller MA, Wright H, Ji C, Cappuccio FP. Cross-sectional study of sleep quantity and quality and amnestic and non-amnestic cognitive function in an ageing population: the English Longitudinal Study of Ageing (ELSA). PLoS One 2014;9:e100991.

96. Lim AS, Yu L, Costa MD, Leurgans SE, Buchman AS, Bennett DA, et al. Increased fragmentation of rest-activity patterns is associated with a characteristic pattern of cognitive impairment in older individuals. Sleep 2012;35: 633-640B.

97. Durmer JS, Dinges DF. Neurocognitive consequences of sleep deprivation. Semin Neurol 2005;25:117-129.

98. Ohayon MM, Vecchierini MF. Daytime sleepiness and cognitive impairment in the elderly population. Arch Intern Med 2002;162:201-208.

99. Craig LA, McDonald RJ. Chronic disruption of circadian rhythms impairs hippocampal memory in the rat. Brain Res Bull 2008;76:141-151.

100. Cohen-Zion M, Stepnowsky C, Johnson S, Marler M, Dimsdale JE, Ancoli-Israel S. Cognitive changes and sleep disordered breathing in elderly: differences in race. $J$ Psychosom Res 2004;56:549-553.

101. Spira AP, Blackwell T, Stone KL, Redline S, Cauley JA, Ancoli-Israel S, et al. Sleep-disordered breathing and cognition in older women. J Am Geriatr Soc 2008;56: 45-50.

102. Kadotani H, Kadotani T, Young T, Peppard PE, Finn L, Colrain IM, et al. Association between apolipoprotein $E$ epsilon4 and sleep-disordered breathing in adults. JAMA 2001;285:2888-2890.

103. Foley DJ, Masaki K, White L, Larkin EK, Monjan A, Redline S. Sleep-disordered breathing and cognitive impairment in elderly Japanese-American men. Sleep 2003;26:596-599.

104. Lyketsos CG, Lopez O, Jones B, Fitzpatrick AL, Breitner $\mathrm{J}$, DeKosky S. Prevalence of neuropsychiatric symptoms in dementia and mild cognitive impairment: results from the cardiovascular health study. JAMA 2002;288:1475-1483.

105. Muangpaisan W, Intalapaporn S, Assantachai P. Neuropsychiatric symptoms in the community-based patients with mild cognitive impairment and the influence of demographic factors. Int $J$ Geriatr Psychiatry 2008;23:699-703.

106. Bombois S, Derambure P, Pasquier F, Monaca C. Sleep disorders in aging and dementia. $J$ Nutr Health Aging 2010;14:212-217.

107. Teng E, Lu PH, Cummings JL. Neuropsychiatric symptoms are associated with progression from mild cognitive impairment to Alzheimer's disease. Dement Geriatr Cogn Disord 2007:24:253-259.

108. Westerberg CE, Mander BA, Florczak SM, Weintraub S, Mesulam MM, Zee PC, et al. Concurrent impairments in sleep and memory in amnestic mild cognitive impairment. J Int Neuropsychol Soc 2012;18:490-500.

109. Hita-Yañez E, Atienza M, Gil-Neciga E, Cantero JL. Disturbed sleep patterns in elders with mild cognitive impairment: the role of memory decline and $A p o E \varepsilon 4$ genotype. Curr Alzheimer Res 2012;9:290-297.

110. Westerberg CE, Lundgren EM, Florczak SM, Mesulam 
$\mathrm{MM}$, Weintraub S, Zee PC, et al. Sleep influences the severity of memory disruption in amnestic mild cognitive impairment: results from sleep self-assessment and continuous activity monitoring. Alzheimer Dis Assoc Disord 2010;24:325-333.

111. Naismith SL, Rogers NL, Hickie IB, Mackenzie J, Norrie LM, Lewis SJ. Sleep well, think well: sleep-wake disturbance in mild cognitive impairment. J Geriatr Psychiatry Neurol 2010;23:123-130.

112. Anderson KN, Bradley AJ. Sleep disturbance in mental health problems and neurodegenerative disease. Nat Sci Sleep 2013;5:61-75.

113. Guarnieri B, Adorni F, Musicco M, Appollonio I, Bonanni E, Caffarra $\mathrm{P}$, et al. Prevalence of sleep disturbances in mild cognitive impairment and dementing disorders: a multicenter Italian clinical cross-sectional study on 431 patients. Dement Geriatr Cogn Disord 2012;33:50-58.

114. Tractenberg RE, Singer CM, Kaye JA. Symptoms of sleep disturbance in persons with Alzheimer's disease and normal elderly. J Sleep Res 2005;14:177-185.

115. Weldemichael DA, Grossberg GT. Circadian rhythm disturbances in patients with Alzheimer's disease: a review. Int J Alzheimers Dis 2010;2010:716453.

116. Loewenstein RJ, Weingartner H, Gillin JC, Kaye W, Ebert M, Mendelson WB. Disturbances of sleep and cognitive functioning in patients with dementia. Neurobiol Aging 1982;3:371-377.

117. Reynolds CF 3rd, Kupfer DJ, Taska LS, Hoch CC, Spiker DG, Sewitch DE, et al. EEG sleep in elderly depressed, demented, and healthy subjects. Biol Psychiatry 1985; 20:431-442.

118. Prinz PN, Vitaliano PP, Vitiello MV, Bokan J, Raskind M, Peskind E, et al. Sleep, EEG and mental function changes in senile dementia of the Alzheimer's type. Neurobiol Aging 1982;3:361-370.

119. Bonanni E, Maestri M, Tognoni G, Fabbrini M, Nucciarone B, Manca ML, et al. Daytime sleepiness in mild and moderate Alzheimer's disease and its relationship with cognitive impairment. J Sleep Res 2005;14:311-317.

120. Desai AK, Grossberg GT. Recognition and management of behavioral disturbances in dementia. Prim Care Companion J Clin Psychiatry 2001;3:93-109.

121. Prinz PN, Vitiello MV, Raskind MA, Thorpy MJ. Geriatrics: sleep disorders and aging. $N$ Engl $J$ Med
1990;323:520-526.

122. Hassainia F, Petit D, Nielsen T, Gauthier S, Montplaisir J. Quantitative EEG and statistical mapping of wakefulness and REM sleep in the evaluation of mild to moderate Alzheimer's disease. Eur Neurol 1997;37:219-224.

123. Petit D, Gagnon JF, Fantini ML, Ferini-Strambi L, Montplaisir J. Sleep and quantitative EEG in neurodegenerative disorders. J Psychosom Res 2004;56:487-496.

124. Bliwise DL. Sleep in normal aging and dementia. Sleep 1993;16:40-81.

125. Ancoli-Israel S, Klauber MR, Jones DW, Kripke DF, Martin J, Mason W, et al. Variations in circadian rhythms of activity, sleep, and light exposure related to dementia in nursing-home patients. Sleep 1997;20:18-23.

126. Mizuno S, Kameda A, Inagaki T, Horiguchi J. Effects of donepezil on Alzheimer's disease: the relationship between cognitive function and rapid eye movement sleep. Psychiatry Clin Neurosci 2004;58:660-665.

127. Yesavage JA, Friedman L, Kraemer H, Tinklenberg JR, Salehi A, Noda A, et al. Sleep/wake disruption in Alzheimer's disease: APOE status and longitudinal course. $J$ Geriatr Psychiatry Neurol 2004;17:20-24.

128. Sperling RA, Aisen PS, Beckett LA, Bennett DA, Craft S, Fagan AM, et al. Toward defining the preclinical stages of Alzheimer's disease: recommendations from the National Institute on Aging-Alzheimer's Association workgroups on diagnostic guidelines for Alzheimer's disease. Alzheimers Dement 2011;7:280-292.

129. Flicker L. Life style interventions to reduce the risk of dementia. Maturitas 2009;63:319-322.

130. Barnes DE, Yaffe K. The projected effect of risk factor reduction on Alzheimer's disease prevalence. Lancet Neurol 2011;10:819-828.

131. Brookmeyer R, Johnson E, Ziegler-Graham K, Arrighi HM. Forecasting the global burden of Alzheimer's disease. Alzheimers Dement 2007;3:186-191.

132. Most EI, Aboudan S, Scheltens P, Van Someren EJ. Discrepancy between subjective and objective sleep disturbances in early- and moderate-stage Alzheimer disease. Am J Geriatr Psychiatry 2012;20:460-467.

133. Thome J, Coogan AN, Woods AG, Darie CC, Häßler F. CLOCK genes and circadian rhythmicity in Alzheimer disease. J Aging Res 2011;2011:383091. 